ARTICLE

Received 22 Nov 2013 | Accepted 21 Feb 2014 | Published 1 Apr $2014 \quad$ DOl: 10.1038/ncomms4489

\title{
Metallodendrimers in three oxidation states with electronically interacting metals and stabilization of size-selected gold nanoparticles
}

Yanlan Wang ${ }^{1}$, Lionel Salmon², Jaime Ruiz ${ }^{1} \&$ Didier Astruc ${ }^{1}$

Metallodendrimers containing redox-robust centres may have applications in molecular redox recognition, sensing, biosensing and catalysis. So far, however, no metallodendrimer is known in several oxidation states. Here we report metallodendrimers with two electronically communicating iron centres that are stable and isolated in both the Fe" and Fe $\mathrm{e}^{\mathrm{III}}$ oxidation states, and in addition as class-II mixed-valent $\mathrm{Fe}^{\text {II } \mathrm{Fe}} \mathrm{F}^{\mathrm{III}}$ complexes. These dendrons are branched to arene-centred dendrimer cores either by Sonogashira coupling or 'click' reactions. The latter reaction involves the introduction of intradendritic 1,2,3-triazolyl ligands, which allows investigation of the selective role of these ligands in intradendritic Au ${ }^{\text {III }}$ coordination and $\mathrm{Au}^{0}$ nanoparticle stabilization. As a result, and using the various metallodendrimers with different oxidation states, small $\mathrm{Au}^{0}$ nanoparticles are intradendritically stabilized by the triazole ligands, whereas with the related non-'click' dendrimers large $\mathrm{Au}^{\mathrm{O}}$ nanoparticles are formed outside the dendrimers and stabilized by a group of dendrimers. 
$\mathrm{T}$ o date, dendrimers and metal nanoparticles (NPs) have been largely involved in materials science including nanomedicine, photonics and supramolecular chemistry ${ }^{1-5}$, and in particular metallodendrimers and dendrimercontaining $\mathrm{NPs}^{2-4,6-11}$ have been efficiently designed for catalysis $^{2-4}$, photophysics ${ }^{7-11}$ and sensing ${ }^{9-13}$. Redox-stable metallodendrimers are a specific class of materials allowing redox anion recognition, sensing ${ }^{2-16}$ and biosensing 14,15 that have been used essentially with ferrocene derivatives ${ }^{12-15}$. Although biferrocene- and silicon-bridged biferrocene-terminated dendrimers are known ${ }^{5,14-16}$, no dendrimers have yet been isolated in several oxidation states owing to instability of the oddelectron species. The flexibility of oxidation-state variation with the maintenance of stability for a large collection of metal centres located at the metallodendrimer periphery is highly desirable, however, because it would allow the design of nanodevices towards applications in molecular nanoelectronics including nanobatteries ${ }^{17}$ and polyelectrolytes ${ }^{18}$.

Here we present the synthesis and redox, electronic and NPstabilization properties of new metallodendrimers in three robust oxidation states including mixed-valent metallodendrimers. The metal centres located at the dendritic periphery are organized in dendrons in such a way that the two metal centres of the dendrons are electronically communicating. Redox reactions of transition-metal complexes ${ }^{19-22}$ are essential to organize molecular electronic communication in nanomaterials ${ }^{23}$. The redox-rich iron centres in the chosen system are $\mathrm{Cp}^{*} \mathrm{Fe}^{\mathrm{II}}$ (dppe)alkynyl units $\left(\mathrm{Cp}^{*}=\eta^{5}-\mathrm{C}_{5} \mathrm{Me}_{5}\right.$, dppe $=1,2$-bis(diphenylphosphino) ethane ${ }^{24}$ that are isolobal to ferrocene and linked in meta position of an aryl bridge. In 1,3,5-trimetallaalkynylbenzene derivatives $24-27$, and in such $\mathrm{Cp}^{*} \mathrm{Fe}^{\mathrm{II}}(\mathrm{dppe})$ derivatives in particular ${ }^{25,26}$, it has been shown by density functional theory calculation and electrochemistry that, unlike in the 1,3,5triferrocenylalkynylbenzene derivatives ${ }^{28}$, the three metals are electronically communicating. We synthesize the dendrons with only two iron-ethynyl groups in 1,3 position, leaving the third ethynyl position free for binding to the dendritic core either by Sonogashira coupling ${ }^{29,30}$ or copper-catalysed azide-alkyne cycloaddition (CuAAC, 'click') reactions ${ }^{31-33}$ with appropriately functionalized dendritic core termini. In this way, metallodendrimers in the three oxidation states $\mathrm{Fe}^{\mathrm{II}} \mathrm{Fe}^{\mathrm{II}}, \mathrm{Fe}^{\mathrm{II}} \mathrm{Fe}^{\mathrm{III}}$ and $\mathrm{Fe}^{\mathrm{III}} \mathrm{Fe}^{\mathrm{III}}$ are synthetically accessible with and without $1,2,3$ triazolyl ligands on the branches, and the latter parameter strongly influences their ability to stabilize and isolate gold NPs (AuNPs) on $\mathrm{HAuCl}_{4}$ reduction. As a result, we demonstrate how the presence and number of these intradendritic ligands is crucial to form well-defined, very small AuNPs.

\section{Results}

Dendron and dendrimer synthesis. Both new bimetallic dendrons 1 and 2 were prepared from the precursor complex $\left[\mathrm{FeCp}^{*}(\mathrm{dppe}) \mathrm{Cl}\right]$ according to Fig. 1 . Treatment of one equiv. of 1,3,5-triethynylbenzene with two equiv. of $\left[\mathrm{FeCp}^{*}(\mathrm{dppe}) \mathrm{Cl}\right]$ and $\mathrm{NH}_{4} \mathrm{PF}_{6}$ in a methanol/tetrahydrofuran (THF) mixture (1:1), followed by deprotonation with $\mathrm{KOBu}^{t}$ produced 1-ethynyl-3,5bis(iron)alkynylbenzene, 1, with $60 \%$ yield, and 1-bromo-3,5bis(iron)alkynylbenzene, 2, was obtained upon reaction of
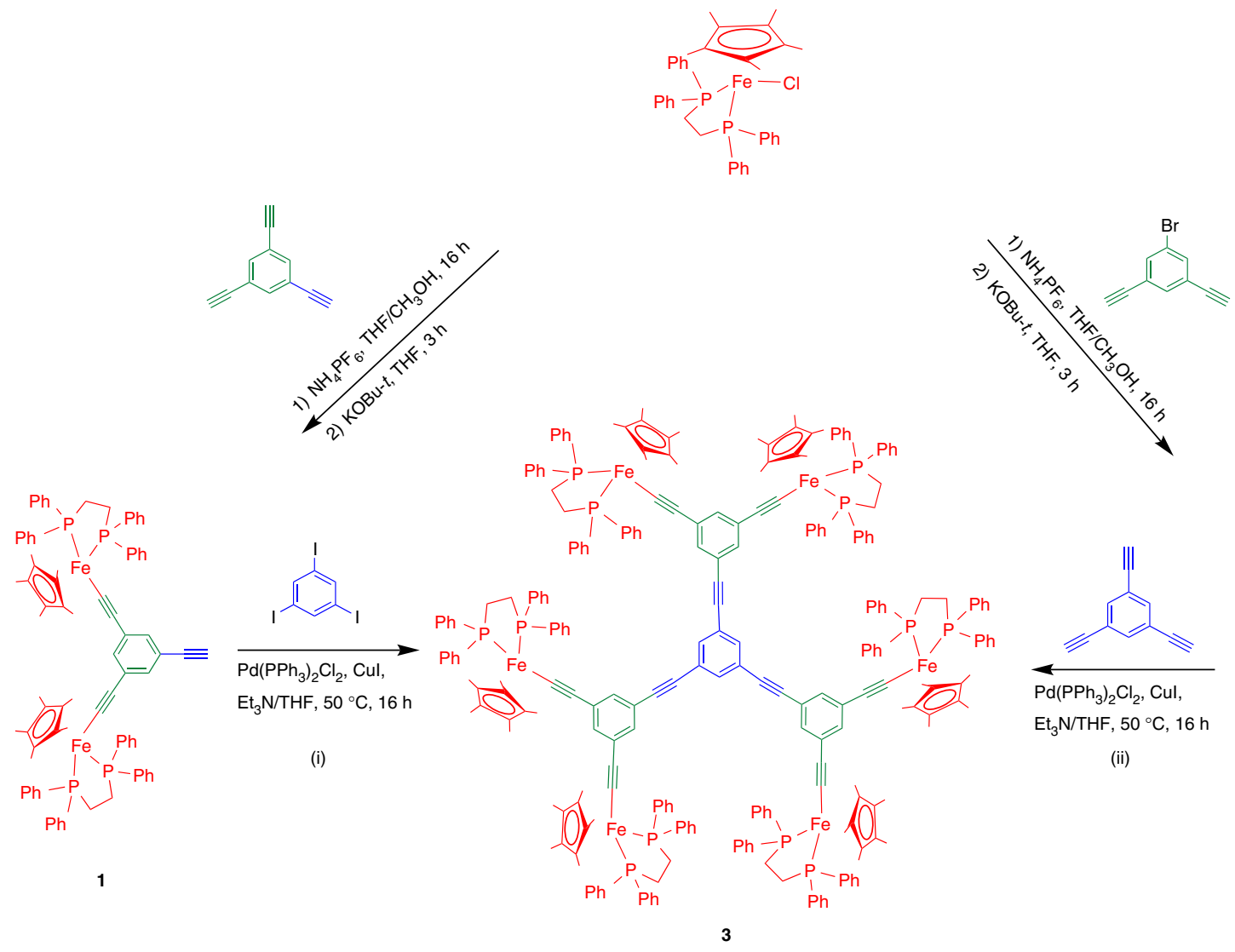

(i)

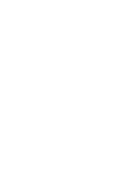

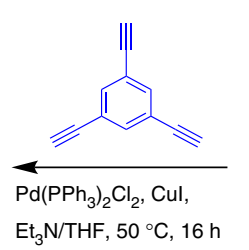

(ii)
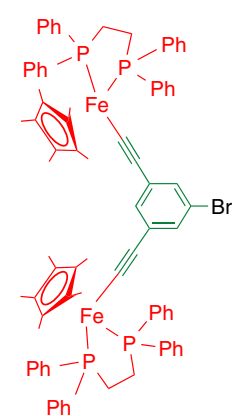

2

Figure 1 | Synthesis of dendrons and dendrimer 3. Reactions of $[\mathrm{FeCp} *(\mathrm{dppe}) \mathrm{Cl}]$ in the presence of $\mathrm{NH}_{4} \mathrm{PF}_{6}$ with $1,3,5$-triethynylbenzene and with 1-bromo-3,5-bis(ethynyl)benzene, both followed by deprotonation with KOBu${ }^{t}$, produced respectively the dendrons $\mathbf{1}$ and $\mathbf{2}$. The hexanuclear compound $\mathbf{3}$ was obtained in two methods under Sonogashira reactions: (i) Sonogashira reaction between dendron $\mathbf{1}$ and 1,3,5-triiodobenzene catalysed by $\mathrm{Pd}\left(\mathrm{PPh}_{3}\right)_{2} \mathrm{Cl}_{2}$ and $\mathrm{Cul}$ and (ii) reaction of dendron 2 with 1,3,5-triethynylbenzene under the same conditions. 
[FeCp* (dppe)Cl] with 1-bromo-3,5-bis(ethynyl)benzene in $70 \%$ yield (Fig. 1). Both complexes $\mathbf{1}$ and $\mathbf{2}$ were isolated as orange microcrystals following standard column chromatography. The characterizations of complexes $\mathbf{1}$ and $\mathbf{2}$ are gathered, respectively, in the Supplementary Figs 1-6 and 7-12.

The hexanuclear compound $\mathbf{3}$ was obtained as deep orange microcrystals using two methods shown in Fig. 1: (i) Sonogashira reaction between dendron $\mathbf{1}$ and 1,3,5-triiodobenzene catalysed by $\left[\mathrm{Pd}\left(\mathrm{PPh}_{3}\right)_{2} \mathrm{Cl}_{2}\right]$ and $\mathrm{CuI}$ (Fig. 1) giving 3 with $50 \%$ yield and (ii) reaction of dendron 2 with 1,3,5-triethynylbenzene under the same conditions $(55 \%$ yield $)$. The ${ }^{31} \mathrm{P}$ NMR spectrum $\left(\mathrm{C}_{6} \mathrm{D}_{6}\right)$ of $\mathbf{3}$ exhibits a broad signal (99.39 $\delta$ p.p.m.) due to the steric hindrance in the hexanuclear complex revealing slow rotation on the NMR timescale. The characterizations of the complex 3 are gathered in Supplementary Figs 13-18.

a

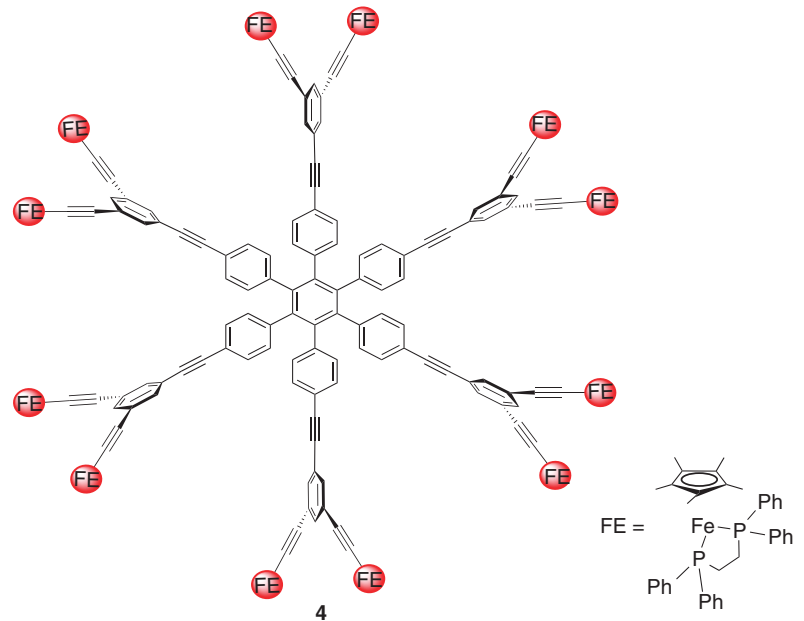

b
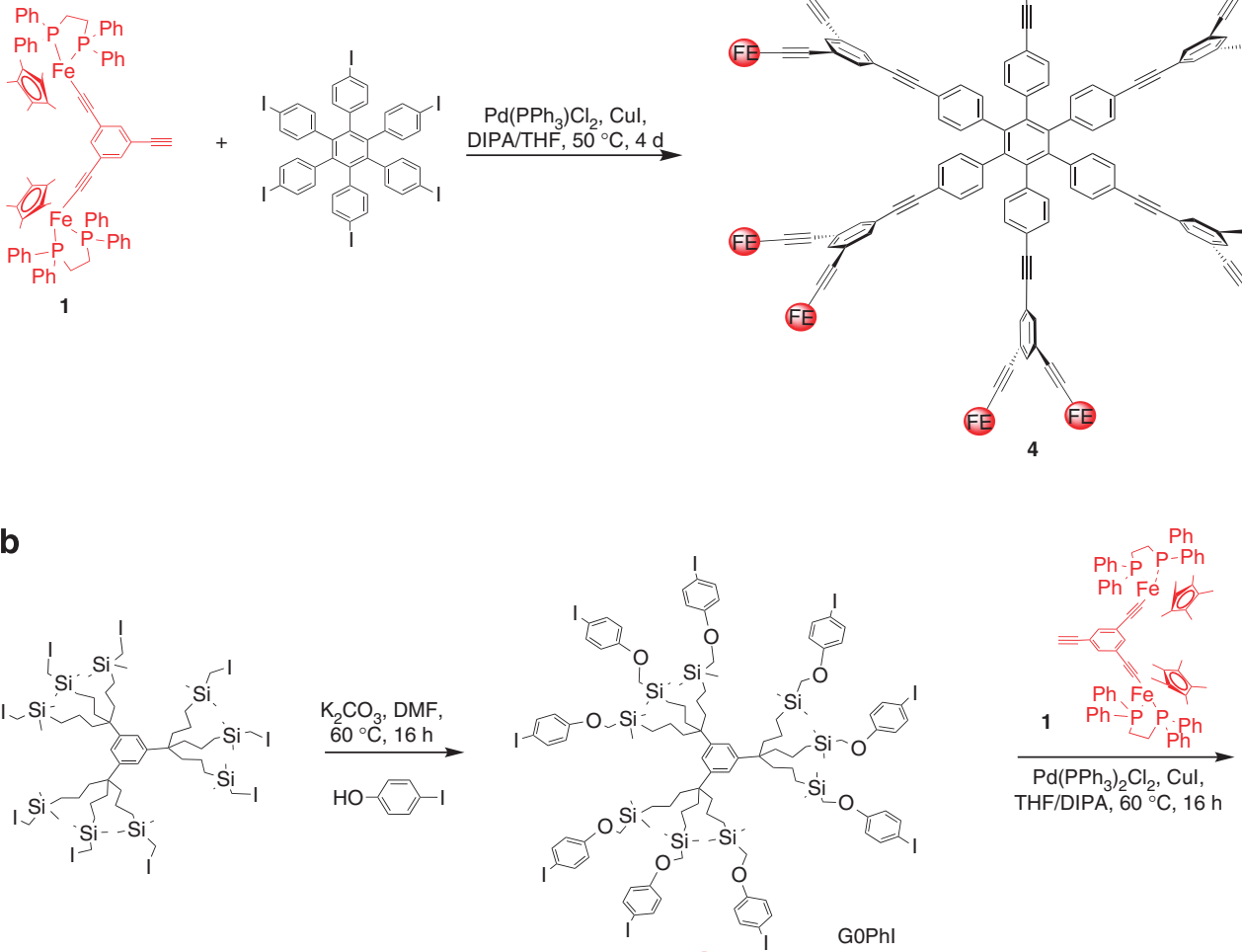

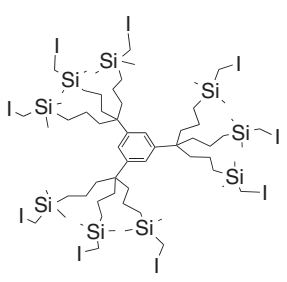
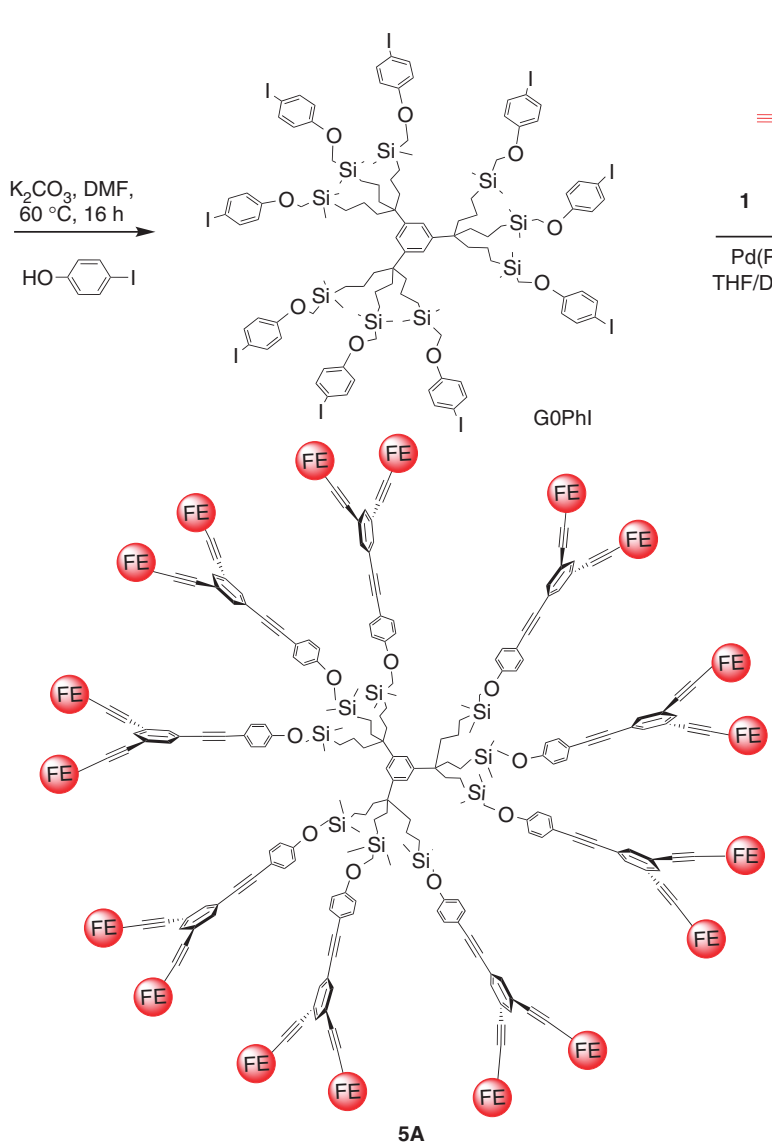

Figure 2 | Syntheses of dendrimers 4 and 5A by Sonogashira reactions. (a) The dodecairon complex 4 was synthesized from the Songashira reaction between dendron 1 and hexakis (4-iodophenyl)-benzene. (b) The p.iodophenyl-terminated dendrimer with nine branches was synthesized from the dendritic core 1,3,5-\{C[( $\left.\left(\mathrm{CH}_{2}\right)_{3} \mathrm{SiMe}_{2} \mathrm{CH}_{2} \mathrm{I}_{3}\right\}_{3}-\mathrm{C}_{6} \mathrm{H}_{3}, \mathrm{GO}-\mathrm{CH}_{2} \mathrm{l}$, by Williamson reaction with p.iodophenol. These dendritic precursors were then functionalized with dendron $\mathbf{1}$ according to Sonogashira reaction to give the dendrimer $\mathbf{5 A}$ 

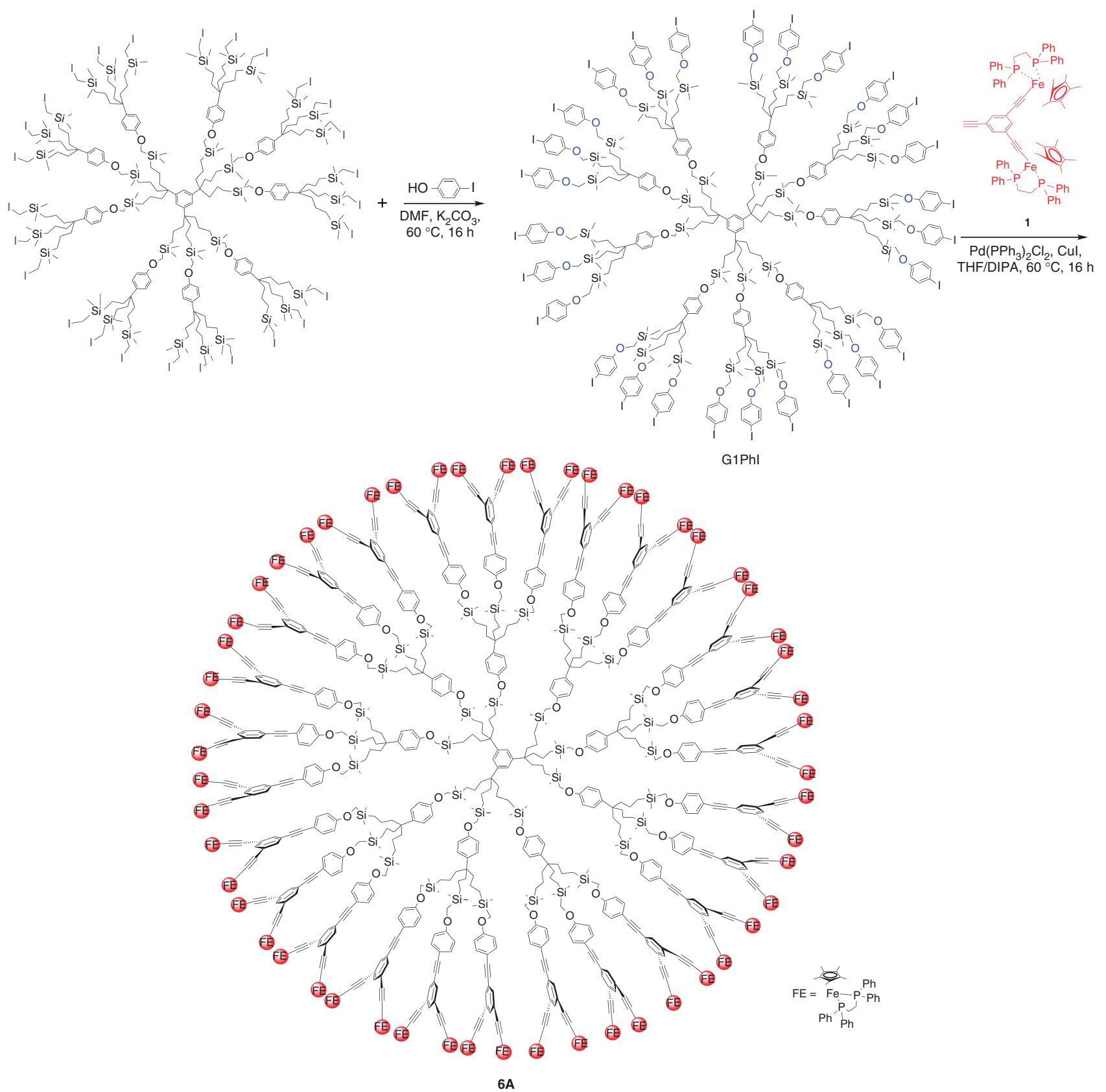

Figure 3 | Syntheses of dendrimer 6A by Sonogashira reaction. The dendrimer 6A was obtained under the identical strategies with dendrimer 5A from 27 iodomethylsilyl-terminated analogue $\mathrm{G} 1-\mathrm{CH}_{2} \mathrm{l}$.

The dodecairon complex 4 was synthesized from the reaction between dendron 1 and hexakis(4-iodophenyl)-benzene catalysed by $\left[\mathrm{Pd}\left(\mathrm{PPh}_{3}\right)_{2} \mathrm{Cl}_{2}\right]$ and $\mathrm{CuI}$ (Fig. 2a). Its infrared spectra show the disappearance of the absorption band around $2,275 \mathrm{~cm}^{-1}$ corresponding to the free alkynyl absorption $\left(v_{\mathrm{C} \equiv \mathrm{C}}\right)$. The characterizations of the complex $\mathbf{4}$ are gathered in Supplementary Figs 19-24.

From the known dendritic cores $1,3,5\left\{\mathrm{C}\left[\left(\mathrm{CH}_{2}\right)_{3} \mathrm{SiMe}_{2-}\right.\right.$ $\left.\left.\mathrm{CH}_{2} \mathrm{I}\right]_{3}\right\}_{3}-\mathrm{C}_{6} \mathrm{H}_{3}, \mathrm{G} 0-\mathrm{CH}_{2} \mathrm{I}$, containing 9 terminal iodomethylsilyl branches (Fig. 2b), and the 27 iodomethylsilyl-terminated analogue $\mathrm{G} 1-\mathrm{CH}_{2} \mathrm{I}$ (Fig. 3), azido- (Figs. 4 and 5) and p.iodophenyl-terminated (Figs 2 and 3) dendrimers were synthesized with 9 and 27 branches by $\mathrm{I} / \mathrm{N}_{3}$ substitution or Williamson reactions with p.iodophenol, respectively. These dendritic precursors were then functionalized with dendron 1 according to Sonogashira (Figs 2 and 3) and 'click' reactions (Figs 4 and 5), respectively. The characterizations of complexes G0-PhI and 5A are gathered in Supplementary Figs 25-27 and 28-33, respectively. Those of complexes G1-PhI and $\mathbf{6 A}$ are gathered in Supplementary Figs $34-36$ and 37-41, respectively, and those of complexes $5 \mathbf{B}$ and $\mathbf{6 B}$ are gathered in Supplementary Figs $42-47$ and 48-53, respectively.

Diffusion-ordered spectroscopy experiments were carried out for the dendrimers $3,4,5 \mathrm{~A}, 5 \mathbf{B}, \mathbf{6 A}$ and $\mathbf{6 B}$. The main goal was to determine the diffusion coefficient $\mathrm{D}$ leading to the hydrodynamic radii of the dendrimer. The spectra also reflected the purity of the products (the measurements were reproducible). The dendrimer size was found to regularly increase with the increase of the number of $\mathrm{Fe}(\mathrm{II})$ units at the dendrimer periphery. Also, the values obtained from 


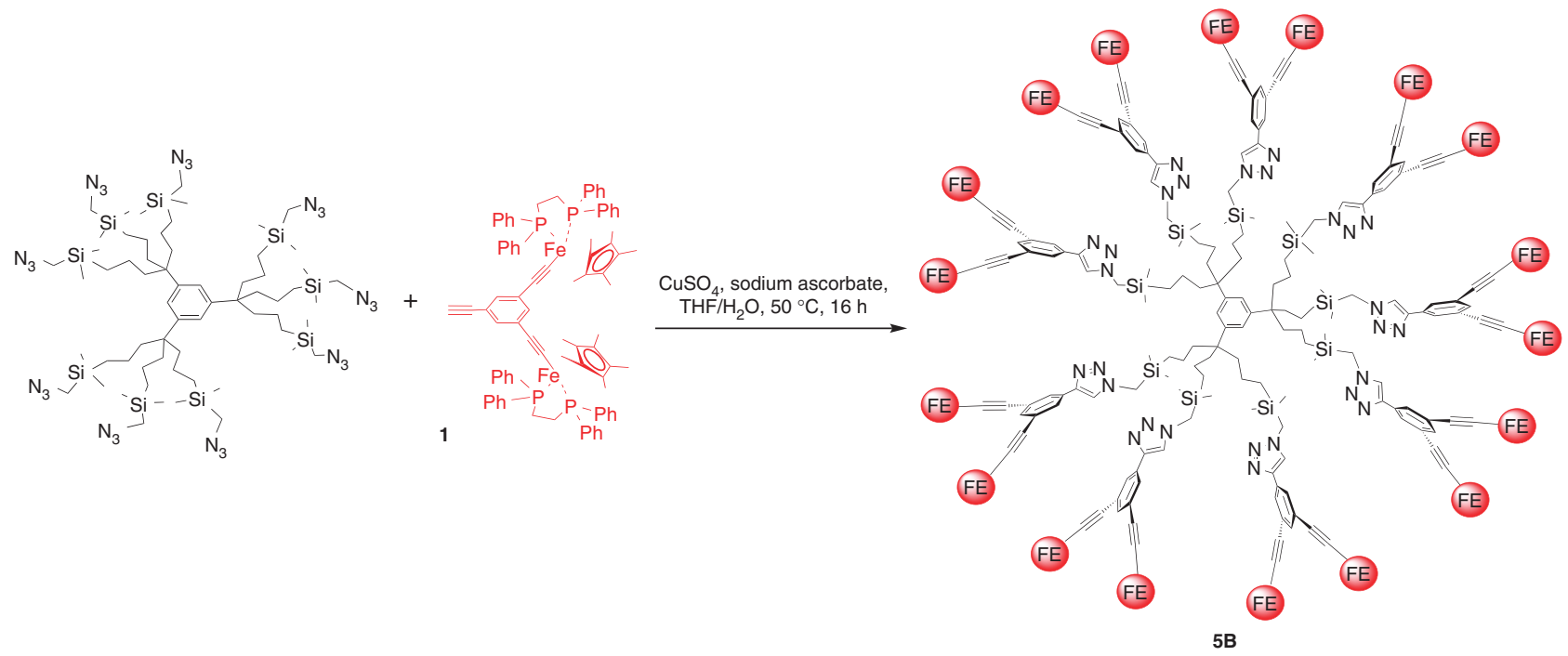

Figure 4 | Syntheses of dendrimer 5B by CuAAC 'click' reaction. Azido-dendrimer with nine branches was synthesized by $\mathrm{I} / \mathrm{N}_{3}$ substitution from the dendritic core 1,3,5-\{C[( $\left.\left(\mathrm{CH}_{2}\right)_{3} \mathrm{SiMe}_{2} \mathrm{CH}_{2} \mathrm{I}_{3}\right\}_{3}-\mathrm{C}_{6} \mathrm{H}_{3}, \mathrm{GO}-\mathrm{CH}_{2}$ l, containing nine terminal iodomethylsilyl. This dendritic precursor was then functionalized with dendron $\mathbf{1}$ according to 'click' reaction to give the dendrimer $\mathbf{5 B}$

dynamic light scattering (DLS) were much larger than the sizes obtained from diffusion-ordered spectroscopy and simulation owing to intermolecular associations ${ }^{34}$. The data are gathered in Table 1.

The cyclic voltammograms of all the metallodendrons and metallodendrimers (Supplementary Fig. 54) were recorded. They showed two reversible waves around -0.5 and $-0.6 \mathrm{~V}$, respectively, with a wave separation $\left(\Delta E_{\mathrm{p}}\right)$ of $0.11-0.13 \mathrm{~V}$ for the metallodendrons (Table 2) with a slight solvent effect and only around $0.070-0.080 \mathrm{~V}$ for the metallodendrimers. For the later, the cyclic voltammogram waves are broad with significant adsorption owing to their large size, which prevents clear wave separation and accuracy in the determination of the potentials, although the comproportionation constants (Table 2) are sufficient for further syntheses of the mixed-valent complexes (vide infra).

Synthesis of the oxidized metallodendrimers. Mixed-valent complexes that are indicators of electronic communication between neighbouring redox sites ${ }^{35}$ are useful tools and models of electronic communication in nanomaterial ${ }^{36}$. The neutral $\mathrm{Fe}^{\mathrm{II}}$ metallodendrimers 3, 4, 5B and $6 \mathrm{~B}$ have been oxidized in dichloromethane (DCM) to the deep-blue fully oxidized $\left(\mathrm{Fe}^{\mathrm{III}} \mathrm{Fe}^{\mathrm{III}}\right)$ metallodendrimers $3\left(\mathrm{PF}_{6}\right)_{6}, \quad \mathbf{4}\left(\mathrm{PF}_{6}\right)_{12}, \quad \mathbf{5 B}\left(\mathrm{PF}_{6}\right)_{18}$, $\mathbf{6 B}\left(\mathrm{PF}_{6}\right)_{54}$ using one equiv. ferricinium hexafluorophosphate $\left(\mathrm{FcH}^{+} \mathrm{PF}_{6}^{-}\right)$per $\mathrm{Fe}$ centre. Oxidation to the green mixedvalent metallodendrimers $3\left(\mathrm{PF}_{6}\right)_{3}, \quad \mathbf{4}\left(\mathrm{PF}_{6}\right)_{6}, \quad \mathbf{5} \mathbf{B}\left(\mathrm{PF}_{6}\right)_{9}$ and 6B $\left(\mathrm{PF}_{6}\right)_{27}$ was conducted using only one equiv. $\mathrm{FcH}^{+} \mathrm{PF}_{6}^{-}$per metallodendron. Alternatively, these mixed-valent metallodendrimers were synthesized on mixing equimolecular amounts of the $\mathrm{Fe}^{\mathrm{II}}$ metallodendrimers and the fully oxidized $\mathrm{Fe}^{\mathrm{III}}$ metallodendrimers (Figs 6 and 7). Ferrocene that was formed in these reactions was removed on washing with pentane, and the oxidized metallodendrimers were characterized by Fourier transform infrared (Supplementary Figs 55-70 and Supplementary Table 1), Mössbauer spectroscopies (Supplementary Fig. 71 and Supplementary Table 2), near-infrared (Supplementary Fig. 72 and Supplementary Table 3), ultraviolet-visible (Supplementary Table 4) and elemental analysis.
The infrared spectra of all the multinuclear iron(II) and iron(III) complexes display a single $\mathrm{C} \equiv \mathrm{C}$ stretching band around 2,040 and $2,000 \mathrm{~cm}^{-1}$, respectively (Supplementary Table 1). In contrast, the infrared spectra of all the mixed-valent complexes show two distinct $\mathrm{C} \equiv \mathrm{C}$ stretching bands at these wavenumbers, providing evidence for localized oxidation states at $10^{13} \mathrm{~s}^{-1}$. The Mössbauer spectra of all the mixed-valent complexes recorded at $78 \mathrm{~K}$ show two quadrupole doublets of approximately equal intensities corresponding to the $\mathrm{Fe}^{\mathrm{II}}$ and $\mathrm{Fe}^{\mathrm{III}}$ states (Supplementary Table 2), indicating localized mixed valency at $10^{-7} \mathrm{~s}^{-1}$. The intervalence charge transfer (IVCT) band (Supplementary Table 3) of the four mixed-valent complexes was found in the near-infrared region in $\mathrm{CD}_{3} \mathrm{COCD}_{3}$. The full width at half height of the band is very close to the theoretical value derived from the near-infrared band position $\lambda_{\max }$ according to Hush's relationship for symmetrical mixed-valent complexes. The ratios $\left(\Delta v_{1 / 2}\right)_{\text {obs }} /\left(\Delta v_{1 / 2}\right)_{\text {calc }}$ were less than 1.15, falling in the 1.1-1.4 range of class-II mixed-valent complexes ${ }^{36-38}$. The UV-vis spectra of all the multinuclear complexes (Supplementary Table 4) display intense absorption bands in the range $250-380 \mathrm{~nm}$ (LC $\pi-\pi^{*}$ transition) and around $400 \mathrm{~nm}$ (metal to ligand charge transfer (MLCT) transition) responsible for the orange colour of the neutral compounds and also present in the deep colour of the mixed-valent/fully oxidized products, whereas the oxidized complexes present two transitions above 550-580 and 645-680 nm explaining their green/blue colour ${ }^{38}$. The mixed-valent properties of all the mixed-valent dendrimers are further discussed in the Supplementary Notes $1-5$.

Stabilization of AuNPs. The availability of metallodendrimers in three oxidation states with $54 \mathrm{Cp}^{*} \mathrm{Fe}(\mathrm{dppe})$ alkynyl termini with interiors containing or not 1,2,3-triazole ligands offered the opportunity to examine the influence of the intradendritic presence of these triazole ligands on the stabilization of AuNPs ${ }^{39-42}$. Indeed, it was possible to start either from $\mathrm{Fe}^{\mathrm{II}} \mathrm{Fe}^{\mathrm{II}}$ metallodendrimers to reduce $\mathrm{Au}^{\mathrm{III}}$ into AuNPs (equation (1)) or from $\mathrm{Fe}^{\mathrm{III}} \mathrm{Fe}^{\mathrm{III}}$ metallodendrimers and $\mathrm{Au}^{\mathrm{III}}$ and to reduce the mixture using excess $\mathrm{NaBH}_{4}$ to $\mathrm{Fe}^{\mathrm{II}} \mathrm{Fe}^{\mathrm{II}}$ and AuNPs (equation (2)). These experiments were conducted with the 

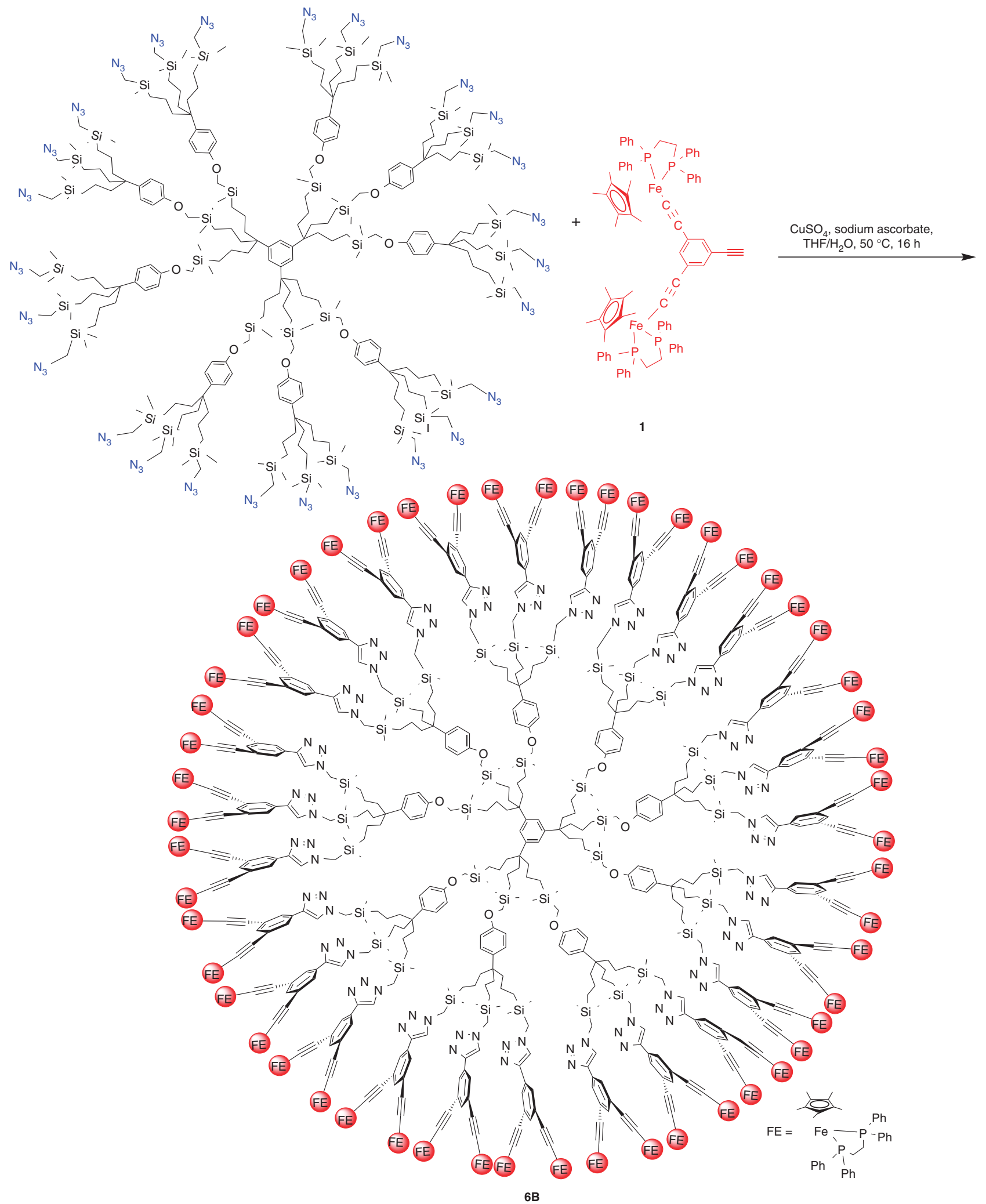

Figure 5 | Syntheses of dendrimer 6B by CuAAC 'click' reaction. The dendrimer 6B was obtained under the identical strategies with dendrimer 5B from 27 iodomethylsilyl-terminated analogue $\mathrm{G} 1-\mathrm{CH}_{2} \mathrm{l}$.

dendrimer $6 \mathrm{~A}$ and $\mathbf{6 B}$ and with dendron 1 for comparison, and the results are gathered in Table 3 and Supplementary Figs 73-82.

$$
3 \mathrm{Fe}^{\mathrm{II}} \mathrm{Fe}^{\mathrm{II}}+\mathrm{Au}^{\mathrm{III}} \rightarrow 3 \mathrm{Fe}^{\mathrm{II}} \mathrm{Fe}^{\mathrm{III}}+\mathrm{Au}^{0}
$$

$$
\mathrm{Fe}^{\mathrm{III}} \mathrm{Fe}^{\mathrm{III}}+\mathrm{Au}^{\mathrm{III}}+\mathrm{NaBH}_{4} \rightarrow \mathrm{Fe}^{\mathrm{II}} \mathrm{Fe}^{\mathrm{II}}+\mathrm{Au}^{0}+\cdots
$$

The AuNPs formed from 6A gave a much more intense plasmon absorption in the ultraviolet-visible spectrum than $6 \mathrm{~B}$ around $530 \mathrm{~nm}$ indicating much larger AuNPs (Fig. 8). Accordingly, the 
smallest AuNPs (cores: 1.4 and $1.9 \mathrm{~nm}$ from equation (1) resp. equation (2)) were obtained with the 'click' metallodendrimer 6B. The Sonogashira metallodendrimer 6A gave larger AuNPs (cores: 3.4 and $3.7 \mathrm{~nm}$ from equation (1) resp. equation (2)), and the metallodendron 1 gave large AuNPs with equation (1) $(20 \mathrm{~nm}$ core), but small AuNPs ( $2 \mathrm{~nm}$ core) according to equation (2) (Fig. 9).

\section{Discussion}

In this work, the syntheses and characterizations of metallodendrimers in three oxidation states have been achieved for the first time, allowing redox interplay exemplified by the formation of AuNPs of selective size depending on the presence and number of intradendritic 1,2,3-triazole ligands.

The metallodendrimers have been designed using interacting metal centres in new bimetallic dendrons. It is the electronic communication between these two iron centres within each bimetallic dendron that provides the occurrence of another stable oxidation state that is class-II mixed-valent in the Robin-Day classification as shown by the splitting of the $\mathrm{C} \equiv \mathrm{C}$ stretching band in infrared and presence of a near-infrared intervalent band.

The choice of the method of dendron connection to dendrimer cores, Sonogashira versus 'click' reaction, further results in the

\section{Table 1 | Size parameters.}

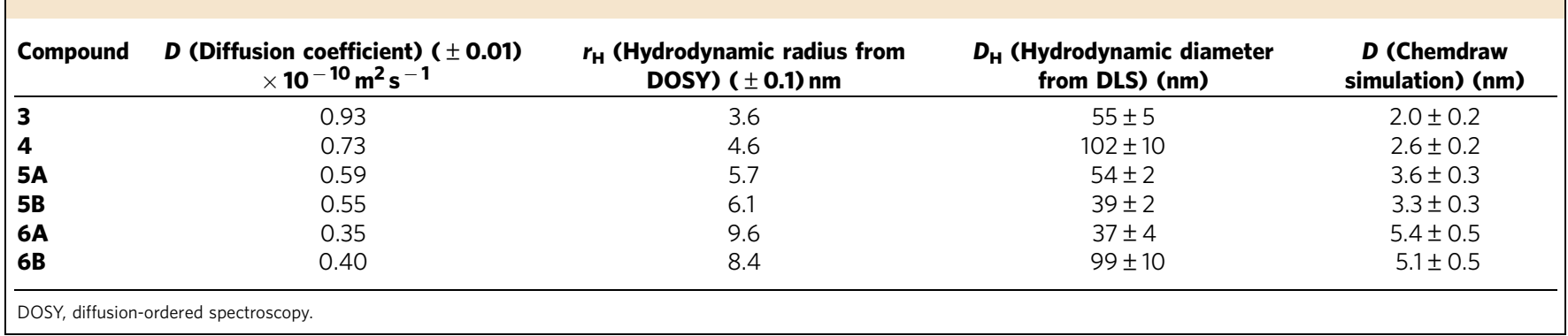

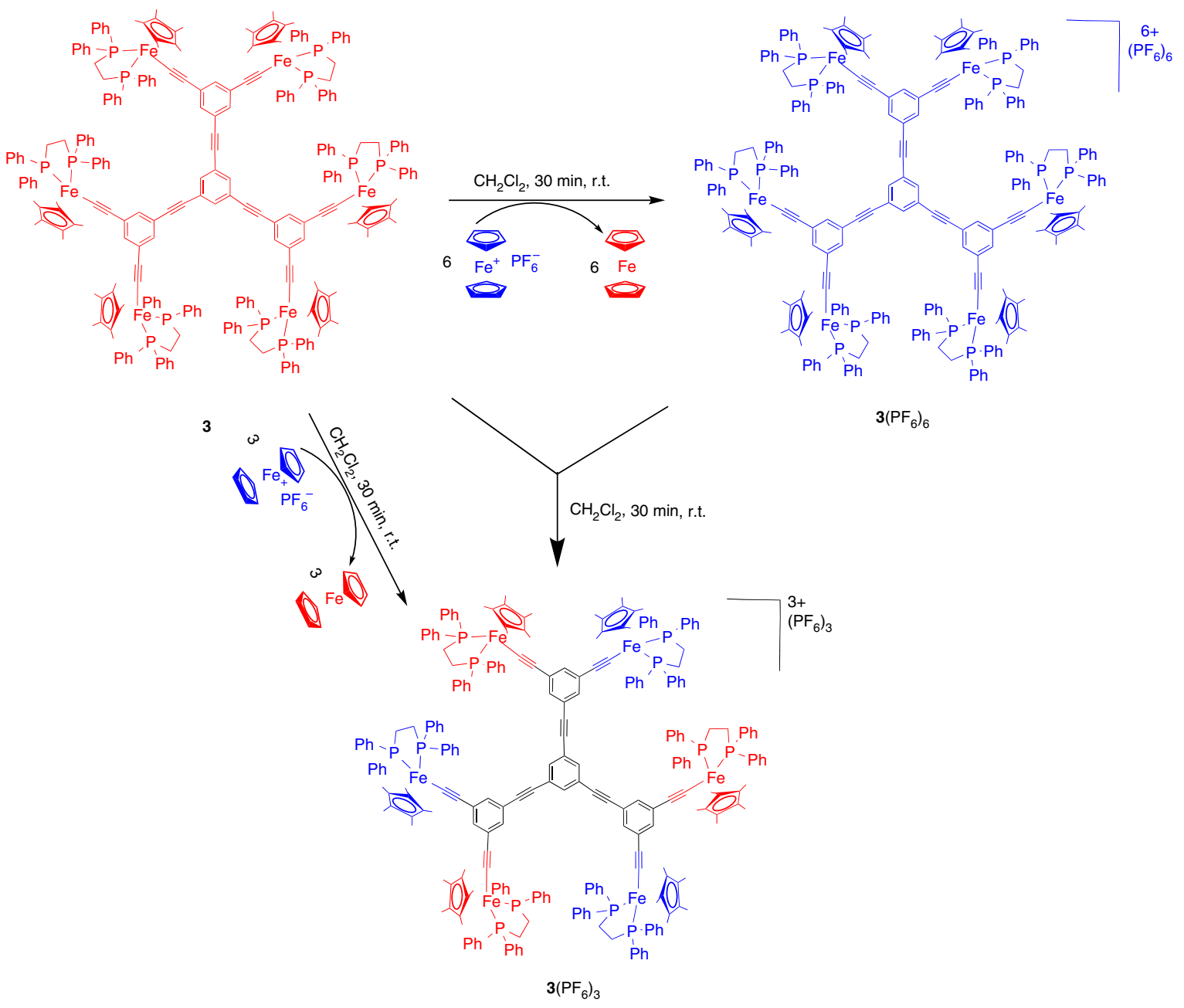

Figure 6 | Oxidation of metallodenrimers. Oxidation of the metallodendrimer $\mathbf{3}$ to the mixed-valent dendrimer $\mathbf{3}\left(\mathrm{PF}_{6}\right)_{3}$ and fully oxidized dendrimer $\mathbf{3}\left(\mathrm{PF}_{6}\right)_{6}$. The Fe $\mathrm{Fe}^{\mathrm{Il}}$ species are in red and the Fe $\mathrm{Fe}^{\mathrm{III}}$ species are in blue. 
a

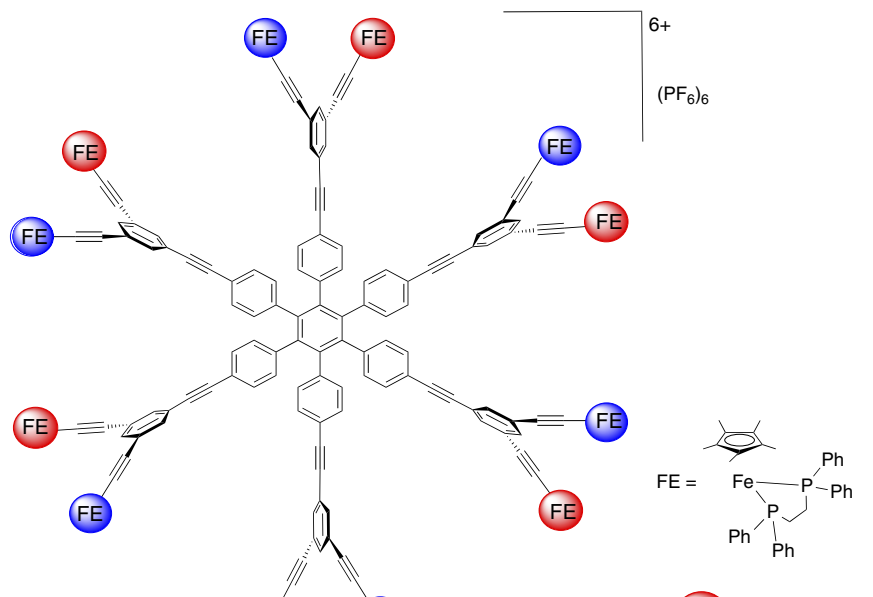

b

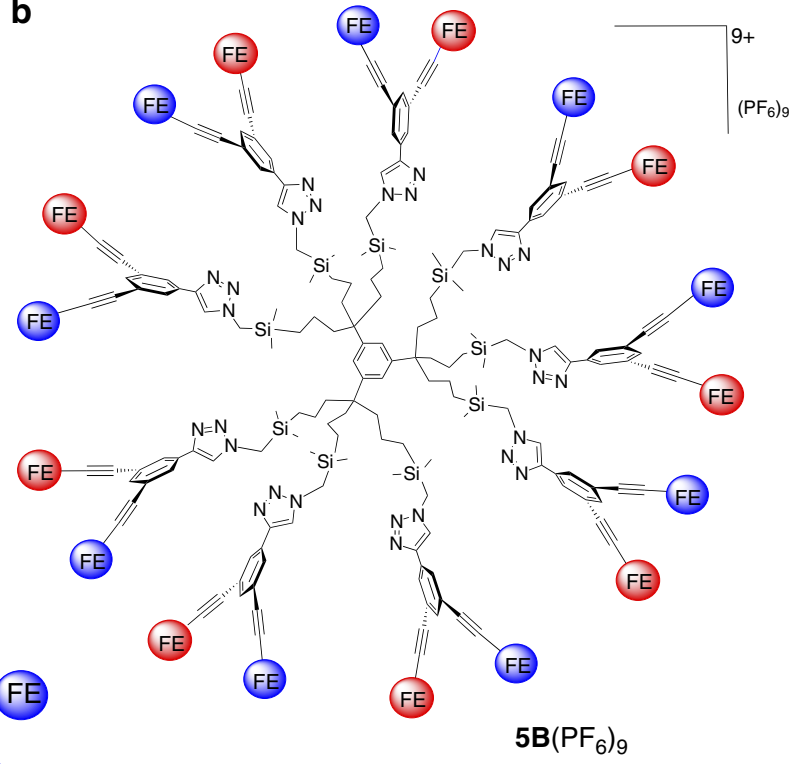

c

$4\left(\mathrm{PF}_{6}\right)_{6}$

FE" :

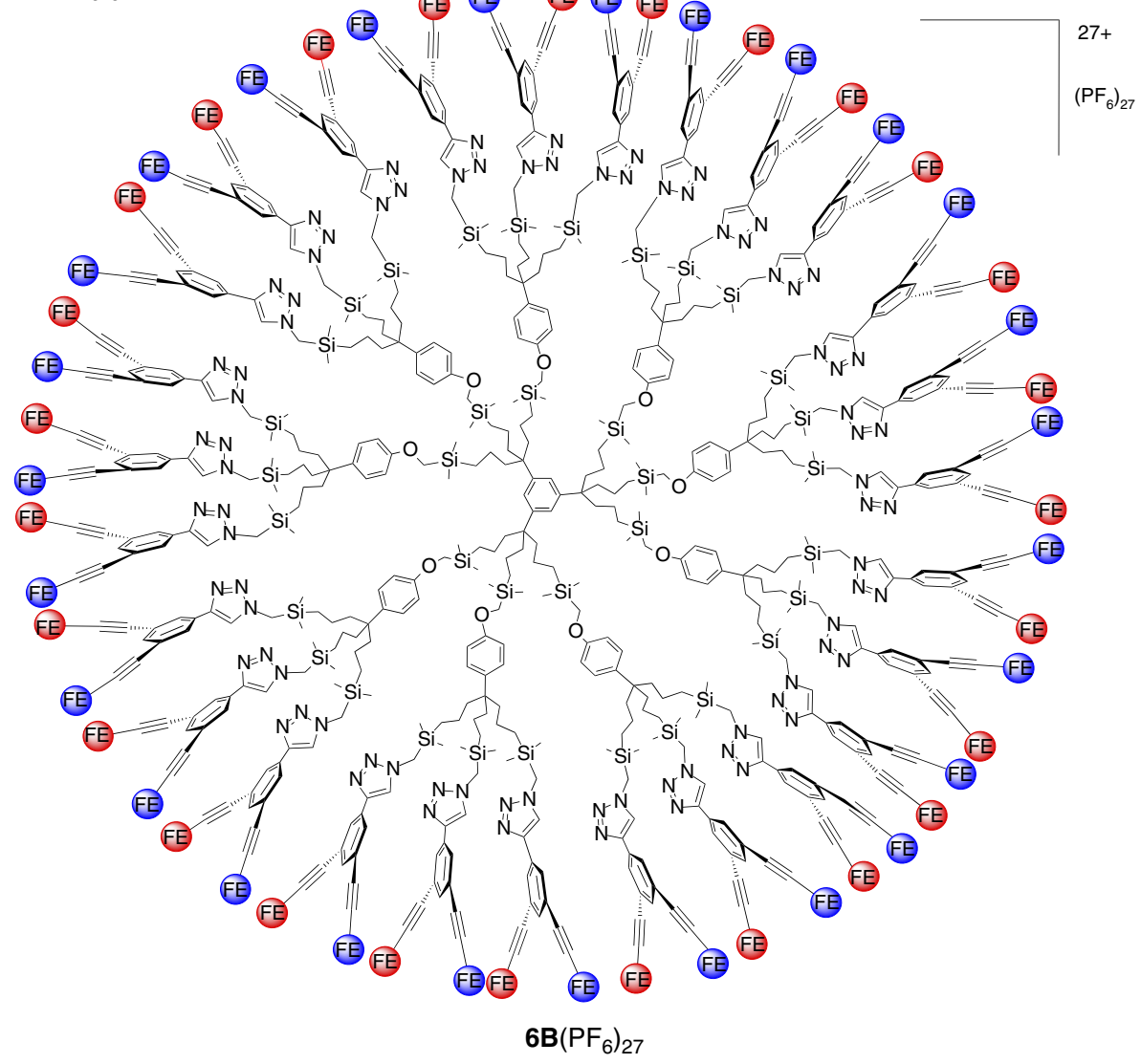

Figure 7 | Oxidation of metallodenrimers. (a-c) The following mixed-valent metallodendrimers $\mathbf{4}\left(\mathrm{PF}_{6}\right), \mathbf{5 B}\left(\mathrm{PF}_{6}\right)_{9}$ and $\mathbf{6} \mathbf{B}\left(\mathrm{PF}_{6}\right)_{27}$ have been obtained analogously. The Fe" species are in red and the Fe $\mathrm{Fe}^{\text {III }}$ species are in blue.

presence or absence of 'clicked' 1,2,3-triazolyl intradendritic ligands. This dendrimer engineering providing electronic flexibility is unique in that the stability and isolation of different dendrimer oxidation states allow examining the influence of the presence and number of these triazole ligands on the intradendritic coordination of $\mathrm{Au}^{\mathrm{III}}$ moieties. As a consequence, it could be shown here that the intradendritic AuNP stabilization specifically induces the formation of small AuNPs.
The results are well taken into account by coordination of $\mathrm{Au}^{3+}$ by the triazole ring in both equations (1) and (2) experiments followed by reduction to small monodisperse AuNPs $(1.4 \pm 0.3 \mathrm{~nm})$ having a core size slightly higher than $27 \mathrm{Au}$ atoms inside a dendrimer, owing to some leaching of $\mathrm{Au}$ atoms among dendrimers (the diameter of a 27-atom AuNP is $1 \mathrm{~nm}$ ). The triazole loosely interacts with the AuNP surface, which contributes to its intradendritic stabilization of these small AuNPs. 


\section{Table 2 | Compared $E_{1 / 2}$ and comproportionation constant} values.

\begin{tabular}{|c|c|c|c|c|}
\hline Compound & $E_{1 / 2}^{\prime}(V)$ & $E_{1 / 2}^{\prime \prime}(V)$ & $\Delta E_{o x}(m V)$ & $\boldsymbol{K}_{\text {com }}^{\prime}$ \\
\hline $\mathbf{1}^{*}$ & -0.50 & -0.63 & 130 & 158 \\
\hline $1^{\dagger}$ & -0.42 & -0.53 & 110 & 72 \\
\hline 2* & -0.50 & -0.63 & 130 & 158 \\
\hline $3^{\dagger}$ & -0.44 & -0.54 & 100 & 49 \\
\hline $4^{*}$ & -0.51 & -0.63 & 120 & 106 \\
\hline $\mathbf{5 A ^ { \dagger }}$ & -0.45 & -0.53 & 80 & 23 \\
\hline $5 B^{\dagger}$ & -0.46 & -0.53 & 70 & 15 \\
\hline 6A $\mathbf{A}^{\dagger}$ & -0.45 & -0.53 & 80 & 23 \\
\hline $6 B^{\dagger}$ & -0.46 & -0.53 & 70 & 15 \\
\hline \multicolumn{5}{|c|}{$\begin{array}{l}\text { K'com, comproportionation constant. } \\
\text { (Cyclic voltammogram using }\left[n-\mathrm{Bu}_{4} \mathrm{~N}\right]\left[\mathrm{PF}_{6}\right] \text { as the supporting electrolyte at } 293 \mathrm{~K} \text {; working and } \\
\text { counter electrodes: } \mathrm{Pt} \text {; reference electrode: } \mathrm{Ag} \text {; scan rate: } 0.200 \mathrm{Vs}^{-1} \text { versus } \mathrm{FeCp}_{2} \text { under the } \\
\text { same concentration }(2 \mathrm{mM}) \text {. } \\
{ }^{*} \text { In } \mathrm{CH}_{2} \mathrm{Cl}_{2} \text {. } \\
\text { † In THF. }\end{array}$} \\
\hline
\end{tabular}

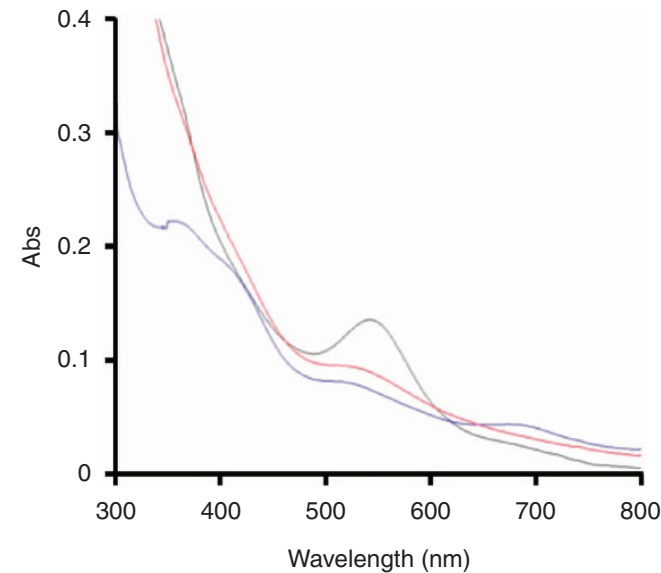

Figure 8 | Compared ultraviolet-visible absorption spectra in $\mathbf{C H}_{\mathbf{2}} \mathbf{C l}_{\mathbf{2}}$. The AuNPs stabilized by reaction of $\mathrm{NaBH}_{4}$ with a mixture of $\mathrm{HAuCl}_{4}$ and dendron $\mathbf{1}\left[\mathrm{PF}_{6}\right]_{2}$ (blue line), $\mathbf{6} \mathbf{A}\left[\mathrm{PF}_{6}\right]_{54}$ (black line) or $\mathbf{6} \mathbf{B}\left[\mathrm{PF}_{6}\right]_{54}$ (red line) under identical conditions giving back the neutral dendrimers (equation (2)).

Table 3 | Properties of AuNPs prepared by the methods of equations (1) and (2).

\begin{tabular}{|c|c|c|c|c|c|c|}
\hline Method & Start & Final & Final colour & Core size (TEM, nm) & Overall size (DLS, $\mathbf{n m})^{*}$ & Plasmon band $(\mathrm{nm})^{\dagger}$ \\
\hline \multirow[t]{3}{*}{ Equation (1) } & 1 & $1^{+}$ & Dark green & $20.2 \pm 3$ & - & 516 \\
\hline & 6A & $6 A^{27+}$ & Dark green & $3.3 \pm 0.5$ & - & 514 \\
\hline & $6 B$ & $6 \mathrm{~B}^{27+}$ & Dark green & $1.4 \pm 0.3$ & - & 537 \\
\hline \multirow[t]{3}{*}{ Equation (2) } & $1^{2+}$ & 1 & Violet & $2.0 \pm 0.3$ & $75 \pm 3$ & 515 \\
\hline & $6 A^{54+}$ & $6 A$ & Violet & $3.7 \pm 0.5$ & $111 \pm 5$ & 525 \\
\hline & $6 \mathrm{~B}^{54+}$ & 6B & Deep violet & $1.9 \pm 0.3$ & $113 \pm 5$ & 545 \\
\hline
\end{tabular}

TEM, transmission electron microscopy

The data were obtained by reducing of the Fe ${ }^{\| \prime} \mathrm{Fe}{ }^{\prime \prime \prime}$ dendrimers to neutral $\mathrm{Fe}^{\| \prime} \mathrm{Fe}$ ll dendrimers using $\mathrm{NaBH}_{4}$.

*DLS of AuNPs synthesized by method of equation (1) is not available owing to the ionic structures.

$\dagger$ The plasmon band of AuNPs obtained by the method of equation (1) is hidden by the ligand-metal charge-transfer band (LMCT) of the mixed-valent metallodendrimer.

a

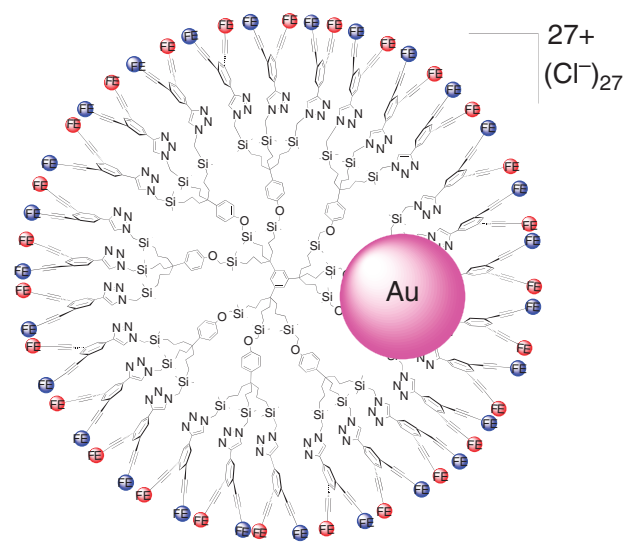

b

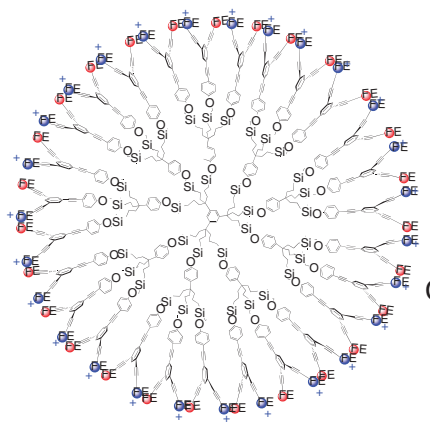

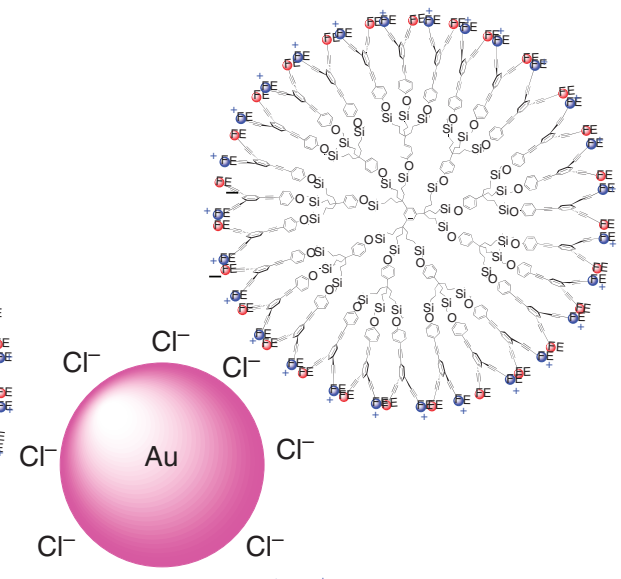

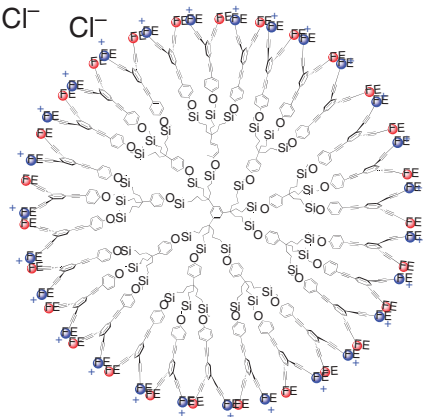

Figure 9 | Schematic picture representing the AuNP stabilized by dendrimers. (a) Intradendritic AuNP stabilization by a 'click' dendrimer $\mathbf{6 B}{ }^{\mathbf{2 7 +}}$ involving AuNP-triazole interactions. (b) Interdendritic stabilization by many 'Sonogashira' dendrimers $\mathbf{6} \mathbf{A}^{\mathbf{2 7 +}}$. It is likely that chloride anions surround the AuNPs in both cases. 

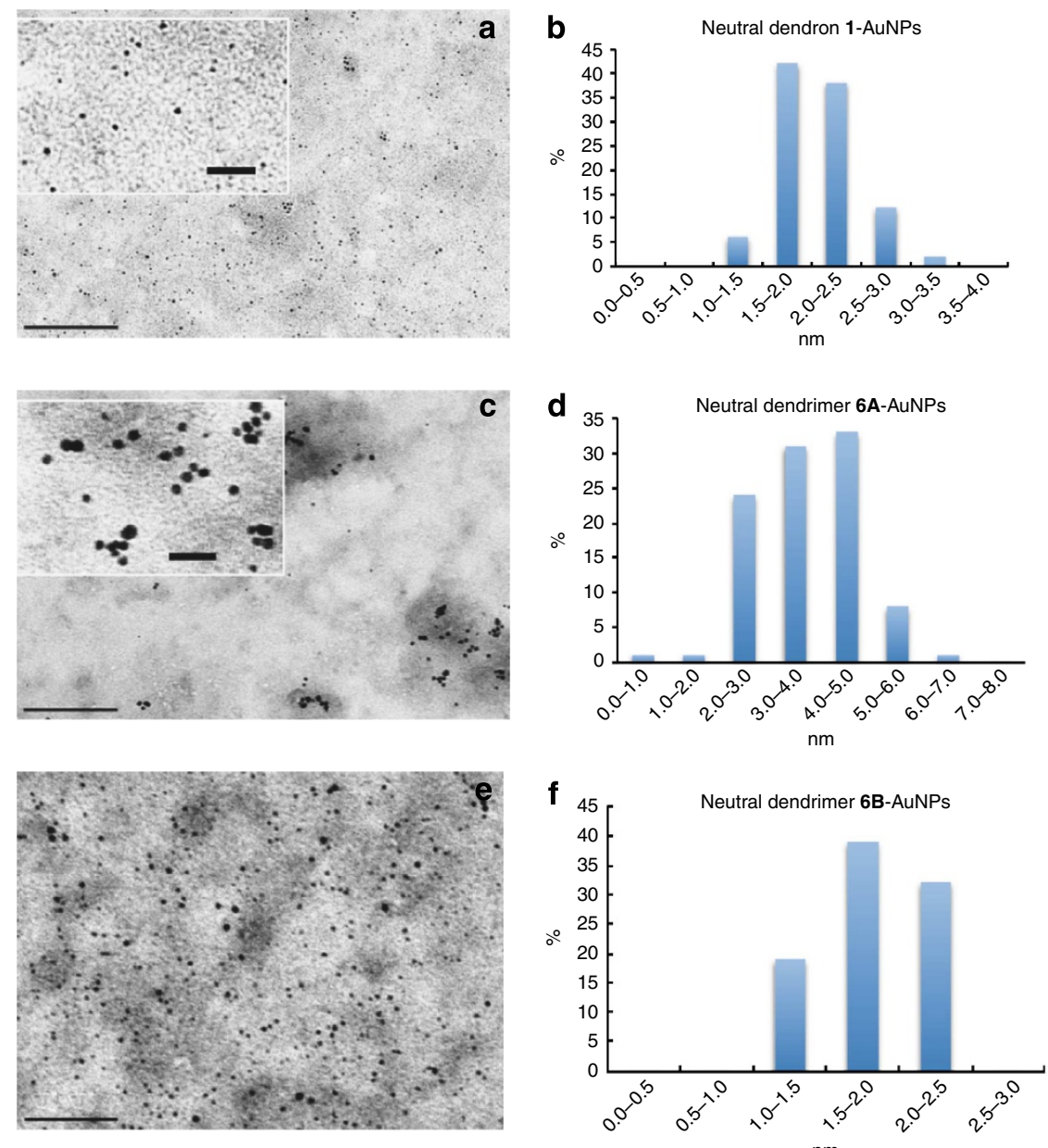

Figure 10 | Transmission electron microscopy of AuNPs. AuNPs stabilized by reaction of $\mathrm{NaBH}_{4}$ with a mixture of $\mathrm{HAuCl}_{4}$ and dendron $\mathbf{1}\left[\mathrm{PF}_{6}\right]_{2}$ (a and $\mathbf{b}$ ), 6A $\left[\mathrm{PF}_{6}\right]_{54}$ (c and $\left.\mathbf{d}\right)$ or $\mathbf{6} \mathbf{B}\left[\mathrm{PF}_{6}\right]_{54}$ (e and $\left.\mathbf{f}\right)$ under identical conditions giving back the neutral dendrimers. Scale bars; $\mathbf{a}$ and $\mathbf{c}, 100 \mathrm{~nm}$ : $\mathbf{a}$ (inset) and $\mathbf{c}$ (inset), $20 \mathrm{~nm} ; \mathbf{e}, 50 \mathrm{~nm}$.

On the contrary, the larger AuNPs stabilized by the Sonagashira dendrimer 6B gather a number of atoms around 1,400, which involves considerable distribution around dendrimer peripheries and final stabilization of each AuNP by several dendrimers, because $\mathrm{Au}^{\mathrm{III}}$ reduction essentially proceeds outside dendrimers, and there are no heteroatom-containing ligand retaining AuNPs inside the dendrimers (Fig. 10). The small dendrons allow the formation of a very large AuNP core surrounded by a large number of dendrons because small dendrons are much less efficient than large dendrimers for NP stabilization.

Remarkably, the AuNP core size of the Au ${ }^{\mathrm{III}}$-click'-dendrimer complexes does not vary considerably with the mode of formation for the dendrimers $\mathbf{6 A}$ and $\mathbf{6 B}$ whatever the synthetic route (equation (1) versus equation (2)). Indeed, the AuNP core size approximately corresponds to the number of $\mathrm{Au}$ atoms generated from the triazolyl-coordinated $\mathrm{Au}^{\mathrm{III}}$ precursors in a single dendrimer. It does for dendron $\mathbf{1}$, however, because AuNP stabilization by borohydride then predominates in equation (2) in the absence of strong dendritic stabilization.

On the other hand, the related non-'click' (Sonogashira) dendrimers generate much larger AuNPs formed outside the metallodendrimers, but also stabilized by a group of metallodendrimers around the AuNP (Supplementary Notes 6 and 7). Such a nanomaterial engineering strategy should be most useful for the design of sophisticated nanosensors, nanocatalysts, nanobatteries and nanopolyelectrolytes in the near future ${ }^{6}$.

\section{Methods}

Synthesis and characterizations of dendron 1. 1,3,5-Triethynylbenzene (150 mg, $1 \mathrm{mmol})$ in $10 \mathrm{ml}$ distilled THF was added to a solution of $\left[\mathrm{FeCp}^{*}(\mathrm{dppe}) \mathrm{Cl}\right](1.56 \mathrm{~g}$, $2.5 \mathrm{mmol}$ ) and $\mathrm{NH}_{4} \mathrm{PF}_{6}(326 \mathrm{mg}, 2 \mathrm{mmol})$ in $12 \mathrm{ml} \mathrm{CH} \mathrm{CH}_{3} \mathrm{OH}$. The suspension was stirred at room temperature (r.t.) for $16 \mathrm{~h}$. The solvent was evaporated in vacuo. The residual solid was dissolved in $5 \mathrm{ml}$ distilled DCM, $100 \mathrm{ml}$ distilled pentane was added and the precipitation was washed with pentane for another two times. The residual solid was dissolved in $10 \mathrm{ml}$ distilled THF, and then potassium tert-butoxide ( $224 \mathrm{mg}, 2 \mathrm{mmol}$ ) was added in a single portion. The mixture was stirred $3 \mathrm{~h}$ under r.t., the solvent was removed in vacuo and the residue was extracted with distilled diethylether to form the crude compound that was further purified by column chromatography (pentane/diethylether $=5 / 1, R_{\mathrm{f}}=0.2$ ) providing dendron 1 as an orange powder $(795.6 \mathrm{mg}$, yield $=60 \%)$. Matrix-assisted laser desorption/ionization time of flight (MALDI-TOF): calc. $\mathrm{m} / z$ for $\mathrm{M}^{+}$ $\left(\mathrm{C}_{84} \mathrm{H}_{82} \mathrm{Fe}_{2} \mathrm{P}_{4}\right)$ 1,327.1, found 1,326.4. Anal. calcd. for $\mathrm{C}_{84} \mathrm{H}_{82} \mathrm{Fe}_{2} \mathrm{P}_{4}: \mathrm{C}, 76.02 ; \mathrm{H}$, 6.23. Found: $\mathrm{C}, 76.32 ; \mathrm{H}, 6.38$. For dendron 2 , a similar procedure was used. See Supplementary Methods for remaining syntheses; full characterization of all other complexes are not described herein.

Synthesis of dendrimer 6A using a Sonogashira reaction. A mixture of dendron 1 (121 mg, 1.5 equiv. for each branch), G1-PhI ( $25 \mathrm{mg}, 1$ equiv. for each branch) and catalytic amount of $\mathrm{Pd}\left(\mathrm{PPh}_{3}\right)_{2} \mathrm{Cl}_{2}(8.5 \mathrm{mg}, 0.2$ equiv. for each branch) and $\mathrm{CuI}$ $(4.6 \mathrm{mg}, 0.1$ equiv. for each branch) were dissolved in the mixed solvent of distilled diisopropylamine (DIPA)/THF $10 \mathrm{ml}$. The solution was stirred overnight at $50^{\circ} \mathrm{C}$ under $\mathrm{N}_{2}$. The solvent was evaporated in vacuo. The residual solid was extracted with $\mathrm{PhCH}_{3} 30 \mathrm{ml}$, the solution was dried with anhydrous $\mathrm{Na}_{2} \mathrm{SO}_{4}$, the solvent was removed in vacuo and the dark red residue was washed three times with distilled diethyl ether $50 \mathrm{ml}$ to remove the excess free ligand. Then the residual solid was dissolved in $1 \mathrm{ml}$ of dry THF, $100 \mathrm{ml}$ of dry $\mathrm{CH}_{3} \mathrm{CN}$ was added to the mixture and compound 6A precipitated as a deep orange solid $(66 \mathrm{mg}$, yield $=70 \%)$. Anal. calcd. for $\mathrm{C}_{2718} \mathrm{H}_{2838} \mathrm{Fe}_{54} \mathrm{P}_{108} \mathrm{Si}_{36} \mathrm{O}_{36}$ : C, 75.13; H, 6.58. Found: C, 75.44; H, 6.47. 
Synthesis of dendrimer 6B by 'click' reaction. To a mixture of G1- $\mathrm{N}_{3}(20 \mathrm{mg}$, $3.6 \times 10^{-3} \mathrm{mmol}, 1$ equiv.) and dendron $1(193 \mathrm{mg}, 0.146 \mathrm{mmol}, 1.5$ equiv. for each branch) in THF $20 \mathrm{ml}, 10 \mathrm{ml}$ of distilled $\mathrm{H}_{2} \mathrm{O}$ was added dropwise, and a solution of $\mathrm{CuSO}_{4} \cdot 5 \mathrm{H}_{2} \mathrm{O}(36.5 \mathrm{mg}, 0.146 \mathrm{mmol}, 1.5$ equiv. for each branch) in $1 \mathrm{ml}$ of $\mathrm{H}_{2} \mathrm{O}$ was slowly added to the mixture at $0{ }^{\circ} \mathrm{C}$, which provoked a colour change from orange to dark brown. The solution of sodium ascorbate $(57.8 \mathrm{mg}$, $0.292 \mathrm{mmol}, 3$ equiv. for each branch) was dropwise added to this mixture at $0{ }^{\circ} \mathrm{C}$, which resulted in a colour change from dark brown to orange. Stirring was continued at $50^{\circ} \mathrm{C}$ under $\mathrm{N}_{2}$ for another $16 \mathrm{~h}$, the solvent was evaporated in vacuo until only the aqueous phase was left, $50 \mathrm{ml}$ of toluene, $50 \mathrm{ml}$ of $\mathrm{H}_{2} \mathrm{O}$ and $3 \mathrm{ml}$ of ammonium hydroxide was added to the solution and the mixture was stirred at r.t. for $30 \mathrm{~min}$ for extraction of the $\mathrm{Cu}$ catalyst. After separation, the organic phase was dried with anhydrous $\mathrm{Na}_{2} \mathrm{SO}_{4}$, and the solvent was removed in vacuo, which gave a deep orange solid that was washed three times with $300 \mathrm{ml}$ diethyl ether to remove the excess free ligands. This procedure yielded the 'click' dendrimer as an orange solid (89.2 mg, 60\%). Anal. calcd. for $\mathrm{C}_{2556} \mathrm{H}_{2757} \mathrm{Fe}_{54} \mathrm{P}_{108} \mathrm{~N}_{81} \mathrm{O}_{9} \mathrm{Si}_{36}: \mathrm{C}, 72.87 ; \mathrm{H}$, $6.60 ; \mathrm{N}, 2.69$. Found: $\mathrm{C}, 72.69 ; \mathrm{H}, 6.40 ; \mathrm{N}, 2.45$. The synthesis and characterizations of 5B were conducted under similar conditions.

Oxidation of the complex $6 \mathrm{~B}$ to $6 \mathrm{BB}\left(\mathrm{PF}_{6}\right)_{27}$. The dendrimer $6 \mathrm{~B}(82 \mathrm{mg}, 2 \times$ $10^{-3} \mathrm{mmol}, 1$ equiv.) was dissolved in $5 \mathrm{ml}$ distilled $\mathrm{DCM}$, and $\left[\mathrm{FeCp}_{2}\right]\left[\mathrm{PF}_{6}\right]$ (17.7 mg, $0.0535 \mathrm{mmol}, 27$ equiv.) was added in a single portion to this solution at r.t., which provoked an immediate colour change from orange to dark green, the solution was stirred for $4 \mathrm{~h}$ at r.t. under $\mathrm{N}_{2}$, the solvent was removed in vacuo until $0.5 \mathrm{ml}$ was left, then $50 \mathrm{ml}$ of distilled pentane was added to this dark green solution and the mixed-valent dendrimer was precipitated. After filtration, the residual solid was washed twice more with $100 \mathrm{ml}$ pentane, and the residue was dried under vacuum to give the mixed-valent dendrimer as a dark solid $(80.9 \mathrm{mg}, 90 \%$ yield. Anal. calcd. for $\mathrm{C}_{2556} \mathrm{H}_{2757} \mathrm{Fe}_{54} \mathrm{P}_{108} \mathrm{~N}_{81} \mathrm{O}_{9} \mathrm{Si}_{36}\left(\mathrm{PF}_{6}\right)_{27}: \mathrm{C}, 66.68 ; \mathrm{H}, 6.04 ; \mathrm{N}, 2.46$. Found: C, 66.77; H, 6.20; N, 2.45. The oxidation of 3, 4, 5B and $\mathbf{6 B}$ by $\left[\mathrm{FeCp}_{2}\right]$ $\left[\mathrm{PF}_{6}\right]$ to the mixed-valent or fully oxidized dendrimers were conducted identically.

Synthesis of AuNPs stabilized by dendrimer $\mathbf{6 B}^{\mathbf{2 7}+}$. The neutral dendrimer $\mathbf{6 B}$ (10 mg, $2.419 \times 10^{-4} \mathrm{mmol}, 1$ equiv. per branch) was dissolved in $2 \mathrm{ml} \mathrm{DCM}$, and the solution of $\mathrm{HAuCl}_{4}\left(0.86 \mathrm{mg}, 2.175 \times 10^{-3} \mathrm{mmol}, 1 / 3\right.$ equiv. $)$ in $2 \mathrm{ml}$ of acetone was slowly added to the mixture at r.t., which provoked a colour change from orange to deep green. Stirring was continued for another $30 \mathrm{~min}$. Infrared $(\mathrm{KBr}): 2,036 \mathrm{~cm}^{-1}\left(v_{\mathrm{C} \equiv \mathrm{C}-\mathrm{Fe}(\mathrm{II})}\right), 2,009 \mathrm{~cm}^{-1}\left(v_{\mathrm{C} \equiv \mathrm{C}-\mathrm{Fe}(\mathrm{III})}\right)$. Ultraviolet-visible: $\lambda_{\max 1}=410 \mathrm{~nm}\left(v_{\Pi-\Pi^{*}}\right), \lambda_{\max 2} / \lambda_{\max 3}=580 / 665 \mathrm{~nm}\left(v_{\mathrm{LMCT}}\right)$. Transmission electron microscopy: $1.4 \pm 0.3 \mathrm{~nm}$. The synthesis and characterizations of AuNPs stabilized by ionic mixed-valent dendron $\mathbf{1}^{+}$or dendrimer $6 \mathrm{~A}^{27+}$ were analogous.

Synthesis of AuNPs stabilized by neutral dendrimer 6B. The neutral dendrimer 6B (5 mg, $1.15 \times 10^{-4} \mathrm{mmol}, 1$ equiv.) was dissolved in $2 \mathrm{ml}$ of DCM, and $\left[\mathrm{FeCp}_{2}\right]$ $\left[\mathrm{PF}_{6}\right]\left(2.1 \mathrm{mg}, 6.22 \times 10^{-3} \mathrm{mmol}, 54\right.$ equiv) was added under stirring, which resulted in an instantaneous colour change from orange to deep blue, and the mixture was stirred at r.t. during $4 \mathrm{~h}$. Then, the solvent was removed in vacuo until $0.5 \mathrm{ml}$ was left, $50 \mathrm{ml}$ of distilled pentane was added to the mixture and the fully oxidized complex precipitated as a dark product. After filtration, this solid was dried under vacuum, dissolved in $2 \mathrm{ml}$ of distilled DCM and a solution of $\mathrm{HAuCl}_{4}$ $\left(1 \mathrm{mg}, 2.54 \times 10^{-3} \mathrm{mmol}\right)$ in $2 \mathrm{ml}$ methanol was added to the mixture under stirring, forming a blue solution. Then, a solution of $\mathrm{NaBH}_{4}(2.35 \mathrm{mg}, 6.2 \times$ $10^{-2} \mathrm{mmol}$, three equiv.) in $1 \mathrm{ml}$ methanol was added dropwise under stirring, leading to a colour change from dark blue to deep violet, which indicated the formation of the AuNPs. The mixture was stirred at r.t. for another $10 \mathrm{~min}$. Infrared $(\mathrm{KBr}): 2,045 \mathrm{~cm}^{-1}\left(v_{\mathrm{C} \equiv \mathrm{C}-\mathrm{Fe}(\mathrm{III})}\right)$. Ultraviolet-visible: $\lambda_{\max 1}=410 \mathrm{~nm}$ $\left(v_{\Pi-\Pi^{*}}\right), \lambda_{\max 2}=545 \mathrm{~nm}$ (plasmon band). Transmission electron microscopy: $1.9 \pm 0.3 \mathrm{~nm}$. The synthesis and characterizations of AuNPs stabilized by the neutral dendron $\mathbf{1}$ or the dendrimer $\mathbf{6 A}$ were conducted analogously.

\section{References}

1. Newkome, G. R. \& Shreiner, C. Dendrimers derived from $1 \rightarrow 3$ branching motifs. Chem. Rev. 110, 6338-6442 (2010).

2. Myers, V. S. et al. Dendrimer-encapsulated nanoparticles: new synthetic and characterization methods and catalytic applications. Chem. Sci. 2, 1632-1646 (2011).

3. Scott, R. J. W., Wilson, O. M. \& Crooks, R. M. Synthesis, characterization and application of dendrimer-encapsulated nanoparticles. J. Phys. Chem. B 109, 692-704 (2005).

4. Astruc, D., Boisselier, E. \& Ornelas, C. Dendrimers designed for functions: from physical, photophysical, and supramolecular properties to applications in sensing, catalysis, molecular electronics, photonics, and nanomedicine. Chem. Rev. 110, 1857-1959 (2010).

5. Casado, C. M., Alonso, B., Losada, J. \& Garcia-Armada, M. P. in Designing Dendrimers (eds Campagna S., Ceroni P., Puntoriero F.) 219-262 (Wiley, 2012).

6. Ochi, Y. et al. Controlled storage of ferrocene derivatives as redox-active molecules in dendrimers. J. Am. Chem. Soc. 132, 5061-5069 (2010).
7. Andronov, A. \& Fréchet, J. M. J. Light-harvesting dendrimers. Chem. Commun. $1701-1710$ (2000)

8. Balzani, V., Bergamini, G. \& Ceroni, P. Chapter 3-Photochemistry and photophysics of metal complexes with dendritic ligands. Adv. Inorg. Chem. 63, 105-135 (2011).

9. Tomalia, D. A., Uppuluri, S., Swanson, D. R. \& Li, J. Dendrimers as reactive modules for the synthesis of new structure-controlled, higher-complexity megamers. Pure Appl. Chem. 72, 2343 (2000).

10. Abruna, H. D. Redox and photoactive dendrimers in solution and on surfaces. Anal. Chem. 76, 310-319 (2004).

11. Wang, S.-H., Shreiner, C. D., Moorefield, C. N. \& Newkome, G. R. Recent progress and applications for metallodendrimers. New J. Chem. 31, 1192-1217 (2007).

12. Astruc, D. Electron-transfer processes in dendrimers and their implication in biology, catalysis, sensing and nanotechnology. Nat. Chem. 4, 255-267 (2012).

13. Beer, P. D. \& Gale, P. A. Anion recognition and sensing: the state of the art and future perspectives. Angew. Chem. Int. Ed. 40, 486-516 (2001).

14. Casado, C. M. et al. Redox-active ferrocenyl dendrimers and polymers in solution and immobilised on electrode surfaces. Coord. Chem. Rev. 185-186, 53-80 (1999).

15. Armada, M. P. G. et al. Electrocatalytical properties of polymethylferrocenyl dendrimers and their applications in biosensing. Bioelectrochemistry 69, 65-73 (2006).

16. Djeda, R. et al. Click syntheses of 1,2,3-triazolylbiferrocenyl dendrimers and the selective roles of the inner and outer ferrocenyl groups in the redox recognition of $\mathrm{ATP}^{2-}$ and $\mathrm{Pd}^{2+}$. Angew. Chem. Int. Ed. 49, 8152-8156 (2010).

17. Arico, A. S., Bruce, P., Scrosati, B., Tarascon, J.-M. \& Schalkwijk, W. Nanostructured materials for advanced energy conversion and storage devices. Nat. Mater. 4, 366-377 (2005).

18. Tatykhanova, G. et al. Metal complexes of amphoteric cryogels based on allylamine and methacrylic acid. Macromol. Symp. 317-318, 18-27 (2012).

19. Flanagan, J. B., Margel, S. \& Bard, A. Electron transfer to and from molecules containing multiple, noninteracting redox centers. Electrochemical oxidation of poly(vinylferrocene). J. Am. Chem. Soc. 100, 4248-4253 (1978).

20. Connelly, N. J. \& Geiger, W. E. Chemical redox agents for organometallic chemistry. Chem. Rev. 96, 877-910 (1996).

21. Geiger, W. E. Organometallic electrochemistry: origins, development, and future. Organometallics 26, 5738-5765 (2007).

22. Nguyen, P., Gomez-Elipe, P. \& Manners, I. Organometallic polymers with transition metals in the main chain. Chem. Rev. 99, 1515-1548 (1999).

23. Eloi, J. C., Chabanne, L., Whittell, G. R. \& Manners, I. Resistive switching in transition metal oxides. Mater. Today 11, 28-36 (2008).

24. Paul, F. \& Lapinte, C. Organometallic molecular wires and other nanoscalesized devices: an approach using the organoiron (dppe) $\mathrm{Cp}^{*} \mathrm{Fe}$ building block Coord. Chem. Rev. 178-180, 431-509 (1998).

25. Fink, H. et al. Ethynylferrocene compounds of 1,3,5-tribromobenzene. Organometallics 16, 2646-2650 (1997).

26. Weyland, T. et al. Bi- and trimetallic $\sigma$-acetylide complexes connected through a phenyl ring in the $\mathrm{Fe}\left(\mathrm{Cp}^{*}\right)$ (dppe) series. Organometallics 16, 2024-2031 (1997).

27. Halet, J.-F. \& Lapinte, C. Charge delocalization versus localization in carbon-rich iron mixed-valence complexes: a subtle interplay between the carbon spacer and the (dppe) $\mathrm{Cp}^{*} \mathrm{Fe}$ organometallic electrophore. Coord. Chem. Rev. 257, 1584-1613 (2013).

28. Diallo, A. K., Absalon, C., Ruiz, J. \& Astruc, D. Ferrocenyl-terminated redox stars: synthesis and electrostatic effects in mixed-valence stabilization. J. Am. Chem. Soc. 133, 629-641 (2011).

29. Sonogashira, K., Tohda, Y. \& Hagihara, N. A convenient synthesis of acetylenes: catalytic substitutions of acetylenic hydrogen with bromoalkenes, iodoarenes and bromopyridines. Tetrahedron Lett. 16, 4467-4470 (1975).

30. Chinchilla, R. \& Najera, C. The Sonogashira reaction: a booming methodology in synthetic organic chemistry. Chem. Rev. 107, 874-922 (2007).

31. Meldal, M. \& Tornøe, C. W. Cu-catalyzed azide - alkyne cycloaddition. Chem. Rev. 108, 2952-3015 (2008)

32. Hein, J. E. \& Fokin, V. V. Copper-catalyzed azide-alkyne cycloaddition (CuAAC) and beyond: new reactivity of copper(I) acetylides. Chem. Soc. Rev. 39, 1302-1315 (2010).

33. Liang, L. \& Astruc, D. The copper(I)-catalyzed alkyne-azide cycloaddition (CuAAC) 'click' reaction and its applications. AN overview. Coord. Chem. Rev. 255, 2933-2945 (2011)

34. Lee, H. \& Ooya, T. Generation-dependent host-guest interactions: solution states of polyglycerol dendrimers of generations 3 and 4 modulate the localization of a guest molecule. Chem. Eur. J. 18, 10624-10629 (2012).

35. Robin, M. B., Melvin, B. \& Day, P. Mixed-valence chemistry-a survey and classification. Adv. Inorg. Chem. Radiochem. 10, 247-403 (1967).

36. Allen, G. C. \& Hush, N. S. Intervalence-transfer absorption. I. Qualitative evidence for intervalence-transfer absorption in inorganic systems in solution and in the solid state. Prog. Inorg. Chem. 8, 357-390 (1967).

37. Richardson, D. E. \& Taube, H. Mixed-valence molecules: electronic delocalization and stabilization. Coord. Chem. Rev. 60, 107-129 (1984). 
38. Weyland, T., Costuas, K., Toupet, L., Halet, J.-F. \& Lapinte, C. Organometallic mixed-valence systems. Two-center and three-center compounds with meta connections around a central phenylene ring. Organometallics 19, 4228-4239 (2000).

39. Chen, X. \& Mao, S. S. Titanium dioxide nanomaterials: synthesis, properties, modifications, and applications. Chem. Rev. 107, 2891-2959 (2007).

40. Xia, Y., Xiong, Y., Lim, B. \& Skrabalak, S. E. Shape-controlled synthesis of metal nanocrystals: simple chemistry meets complex physics? Angew. Chem. Int. Ed. 48, 60-103 (2009).

41. Saha, K., Agasti, S. S., Kim, C., Li, X. \& Rotello, V. M. Gold nanoparticles in chemical and biological sensing. Chem. Rev. 112, 2739-2779 (2012).

42. Daniel, M.-C. \& Astruc, D. Gold nanoparticles: assembly, supramolecular chemistry, quantum-size-related properties, and applications toward biology, catalysis, and nanotechnology. Chem. Rev. 104, 293-346 (2004).

\section{Acknowledgements}

We gratefully acknowledge the financial support by the China Scholarship Council (CSC) from China (PhD grant to Y.W.), the University of Bordeaux and the Centre National de la Recherche Scientifique (CNRS).

\section{Author contributions}

Y.W. and D.A. conceived and designed the experiments and wrote the paper. Y.W. performed the experiments. Y.W. and J.R. conducted the electrochemical measurements. L.S. conducted Mössbauer and transmission electron microscopic experiments.

\section{Additional information}

Supplementary Information accompanies this paper at http://www.nature.com/ naturecommunications

Competing financial interests: The authors declare no competing financial interests.

Reprints and permission information is available online at http://npg.nature.com/ reprintsandpermissions/

How to cite this article: Wang, Y. et al. Metallodendrimers in three oxidation states with electronically interacting metals and stabilization of size-selected gold nanoparticles. Nat. Commun. 5:3489 doi: 10.1038/ncomms4489 (2014). 